\title{
Granuloma formation in patients receiving BCG immunotherapy
}

\author{
J. A. WhitTAKER, D. P. BENTLEY, G. R. MELVILle-JONES ${ }^{1}$, AND \\ A. J. SLATER
}

From the Departments of Haematology and Pathology ${ }^{1}$, University Hospital of Wales and Welsh National School of Medicine, Heath Park, Cardiff CF 4 XN

SYNOPSIS Eleven patients with acute myeloblastic leukaemia have received repeated intravenous injections of BCG containing 4-9 $\times 10^{8}$ live organisms per millilitre. Non-caseating epithelioid granulomas, sometimes with giant-cell formation, have been demonstrated in eight bone marrow aspirates. Seven patients had granulomas in the liver, three in the lung, one in the spleen, one in lymph nodes, and one in a skin biopsy. One patient had a raised serum alkaline phosphatase, but none of the patients had any illness which could be related to the presence of granulomas. Granuloma formation appeared more extensive in four patients who were probably anergic before BCG treatment. Until the significance of this finding becomes clear great care should be taken when giving BCG by the intratumour or intravenous routes to potentially immunoincompetent patients.

The possibility of treating cancer by stimulating the patient's response to his own tumour cells has led to the use of BCG as an active non-specific immunotherapeutic agent. Preliminary results indicate that length of survival and remission duration may be prolonged when BCG is used in the treatment of acute myelogenous leukaemia (AML) (Powles et al, 1973; Gutterman et al, 1974a; Vogler and Chan, 1974) and malignant melanoma (Gutterman et al, 1974b) although more comprehensive studies are needed before definite conclusions can be reached. Hepatic dysfunction, including granulomatous hepatitis, has been seen in three patients receiving BCG by intratumour injection (Hunt et al, 1973; Sparks et al, 1973).

This paper describes a prospective study of liver function and an attempt to define the extent of granuloma formation in a group of patients with AML receiving BCG by the intravenous route.

\section{Patients and methods}

Eleven patients reached complete remission (MRC, 1963) from acute myeloblastic leukaemia after receiving five to nine courses of daunorubicin, 1.5 $\mathrm{mg} / \mathrm{kg}$ by a single intravenous infusion, and cytosine

Received for publication 30 December 1975 arabinoside, $1.0 \mathrm{mg} / \mathrm{kg}$ every 12 hours for five days intravenously. Intervals between treatment were from five to seven days. Maintenance chemotherapy was given on one day of each month with daunorubicin at the remission induction dosage and with cytosine arabinoside, $1.0 \mathrm{mg} / \mathrm{kg}$ as an eight-hour infusion in saline. When a total dose of $600 \mathrm{mg}$ daunorubicin had been reached, doxorubicin, 1.0 $\mathrm{mg} / \mathrm{kg}$, was substituted. In addition, 14 days after each chemotherapy, all patients received BCG (Glaxo freeze-dried preparation containing 4-9 $\times 10^{6}$ live organisms $/ \mathrm{ml}$ ). This was given intravenously using the careful technique previously described (Whittaker et al, 1973).

Blood films were examined every two weeks and bone marrow aspirates and microtrephines every three months, or whenever alterations of blood counts or abnormalities of blood films were seen. Monthly tests of liver function included serum bilirubin, serum aspartate transaminase (SGOT), serum hydroxybutyrate dehydrogenase (SHBD), and alkaline phosphatase. Liver biopsies were performed using a Menghini needle; one patient had an antemortem lung biopsy, and full postmortem examinations were performed on two patients who died with relapsed AML. Delayed cutaneous hypersensitivity was evaluated using 1:1000 PPD and Candida skin test antigen in all patients before BCG had been given and again after treatment. 


\section{Results}

Clinical jaundice and biochemical abnormalities of liver function were unusual in these patients. Transient clinical jaundice occurred in two patients but disappeared in case 7 when an oestrogencontaining contraceptive pill was discontinued. The jaundice in case 1 was associated with raised SGOT and SHBD levels at the time of terminal AML relapse. The alkaline phosphatase has been raised (55-72 IU/litre) in case 8 on three successive occasions, but at no time has the patient had clinical evidence of liver disease. Liver function tests have remained normal throughout in all other patients.

Remission marrow aspirates were repeatedly performed in all 11 patients, and well-formed epithelioid granulomas without caseation, but occasionally with giant-cell formation (fig 1), were seen in eight patients (table).

Similar granulomas were found in five of seven antemortem liver biopsies (fig 2) and in one antemortem lung biopsy (fig 3). Two patients died with AML in relapse; case 2 had occasional granulomas in the lung but not in the liver, spleen or other organs examined; case 7 had well-formed granulomas in the liver, spleen, lymph nodes, and lung, although the liver granulomas could not be demonstrated in a liver biopsy two months before death.

Duration of remission and survival is shown in the table. There is no obvious relationship between $\underline{\vec{\sigma}}$ length of remission or survival and the occurrence of granulomas. Patients who were initially anergic, as $\stackrel{\oplus}{\stackrel{P}{?}}$ judged by skin testing $(1,9,10$, and 11 in the table), had more extensive and well-formed granulomas 흠 than patients who were immunocompetent.

All patients had pyrexia of approximately $24 \stackrel{\mathbb{\complement}}{\complement}$ hours' duration (maximum 72 hours) after BCG, ๗ but during the month between BCG treatments all $\rightarrow$ patients remained well. We were unable to culture? BCG organisms from venous blood samples taken $\vec{\omega}$ more than one hour after BCG treatment, and 9 neither BCG nor tubercle bacilli could be isolated from the marrow or liver biopsy specimens. Recently iु Mycobacterium tuberculosis has been grown from ${ }_{\infty}$ the sputum of one patient (case 8).

\section{Discussion}

The complications of BCG in patients with malignant disease are essentially similar whether the route을 of administration is intradermal, intratumour or $\stackrel{\text { s }}{\rightarrow}$ intravenous (Powles et al, 1973; Gutterman et al, $\overrightarrow{0}$ 1974a; Vogler and Chan, 1974; Gutterman et al, ুે 1974b; Whittaker and Slater, unpublished observation), although intratumour injection has causedo more severe reactions than intradermal injections when high concentrations of BCG organisms haved been given (Gutterman et al, 1974b). Occasionally?

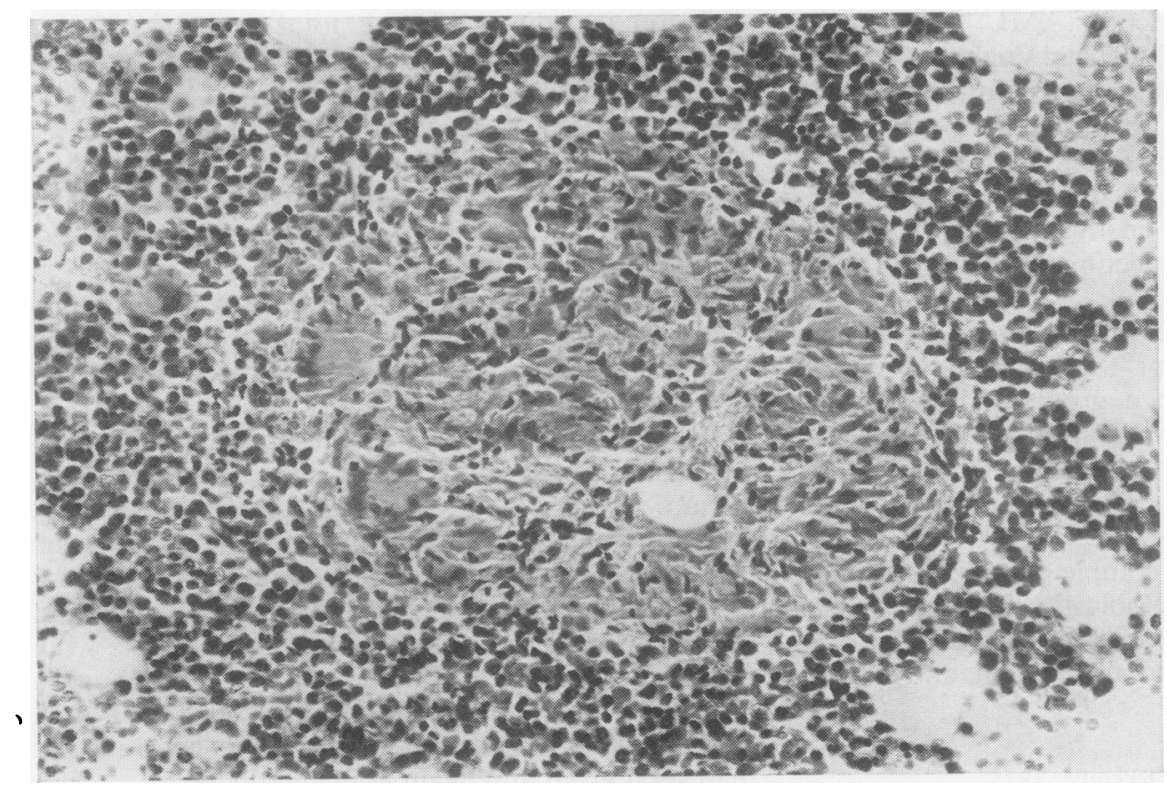

Fig 1 Epithelioid granuloma showing giant-cell formation. Bone marrow from case 9. $\times 77$ 


\begin{tabular}{|c|c|c|c|c|c|c|c|c|c|}
\hline \multirow[t]{3}{*}{ Patient } & \multirow{3}{*}{$\begin{array}{l}\text { Marrow } \\
\text { Aspirate }\end{array}$} & \multirow{3}{*}{$\begin{array}{l}\text { Liver } \\
\text { Biopsy }\end{array}$} & \multirow[t]{3}{*}{ Other Granuloma } & \multicolumn{4}{|c|}{ Skin Testing } & \multirow{3}{*}{$\begin{array}{l}\text { Duration of First } \\
\text { Remission } \\
\text { (weeks) }\end{array}$} & \multirow{3}{*}{$\begin{array}{l}\text { Duration of } \\
\text { Survival } \\
\text { (weeks) }\end{array}$} \\
\hline & & & & \multicolumn{2}{|c|}{ Pre-treatment } & \multicolumn{2}{|c|}{ Post-treatment } & & \\
\hline & & & & $P P D$ & Candida & $P P D$ & Candida & & \\
\hline 1 & 2 & ND & & - & - & ND & ND & 24 & 69 \\
\hline 2 & 1 & 0 & Lung* & + & - & + & - & 30 & 76 \\
\hline 3 & 2 & 2 & & + & - & + & - & 30 & $119+$ \\
\hline 4 & 1 & ND & Lung & ++ & ++ & ++ & ++ & $91+$ & $111+$ \\
\hline 5 & 0 & ND & & - & ++ & ND & ND & 12 & 33 \\
\hline 6 & 0 & 0 & & + & - & + & - & $75+$ & $104+$ \\
\hline 7 & 0 & 0 & Liver*, spleen* & + & - & + & - & 21 & 64 \\
\hline 8 & 2 & 1 & Lymph nodes*, lung* & + & - & + & - & $74+$ & $90+$ \\
\hline 9 & 3 & 2 & Skin (injection site) & - & - & + & - & $48+$ & $53+$ \\
\hline 10 & 2 & 1 & & - & - & - & - & $52+$ & $68+$ \\
\hline 11 & 2 & 3 & & - & - & + & - & 25 & $45+$ \\
\hline
\end{tabular}

Table Granuloma formation and other findings in patients given BCG intravenously

* no lesion seen 1 granuloma present 2 well-formed granuloma 3 numerous well-formed granulomas

liver granulomas have occurred after intratumour BCG (Hunt et al, 1973; Sparks et al, 1973), and patients receiving BCG intradermally (Vogler and Chan, 1974) or by intratumour injection (Hunt et al, 1973; Sparks et al, 1973) have shown various transient disturbances of liver function, including jaundice, palpable livers, raised alkaline phosphatase, and raised SGOT levels. These patients have had liver biopsies because of debilitating illness associated with persistent fever, and no published study of liver biopsy findings following intradermal BCG in patients with malignancy is available. However, it is likely that granulomas occur in these patients, and Gormsen (1956) has demonstrated epithelioid granulomas in the liver, lungs, spleen, and kidneys in 13 of 20 asymptomatic patients dying from a variety of causes six weeks to $\mathbf{4 0}$ months after BCG vaccination. BCG given subcutaneously or intravenously to animals spreads in an identical manner (Ström and Widström, 1951) and intravenous spread of the organism is unlikely to be the main factor in the production of complications. When used in a low concentration of live organisms (maximum 0.4-0.9 $\times 10^{6}$ monthly) BCG has been

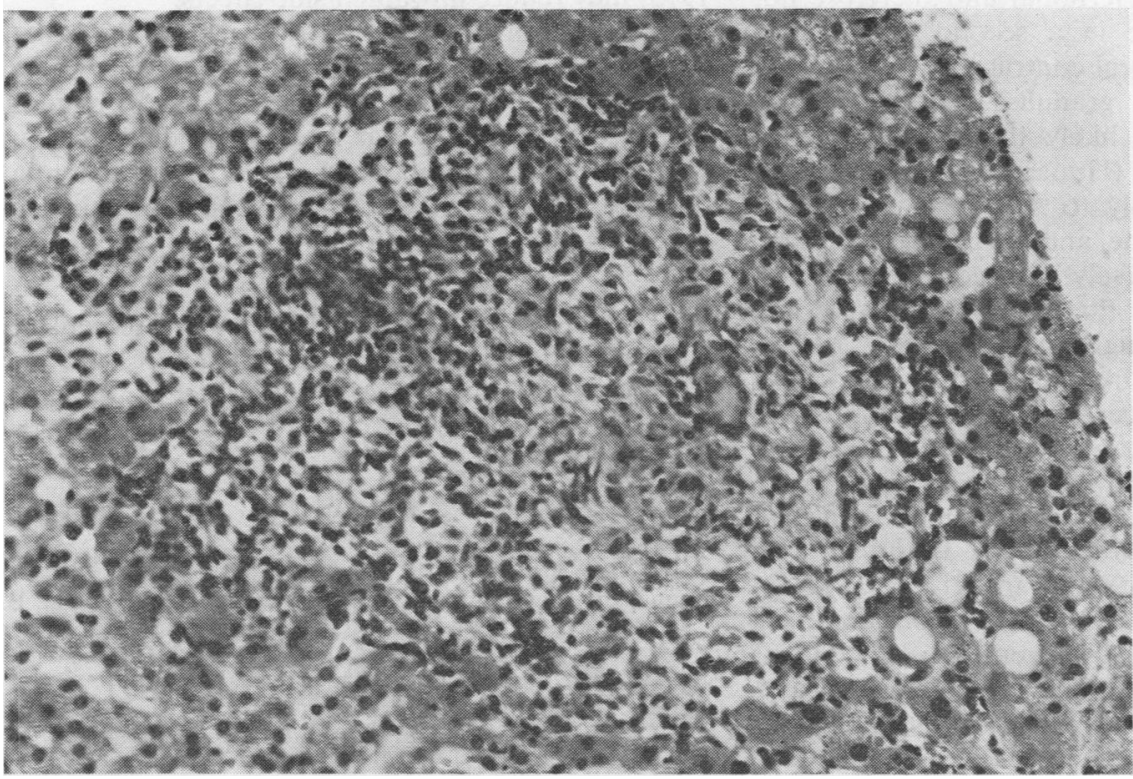

Fig 2 Liver biopsy specimen (case 3) showing giant-cell formation in an epithelioid granuloma. $\times 180$ 


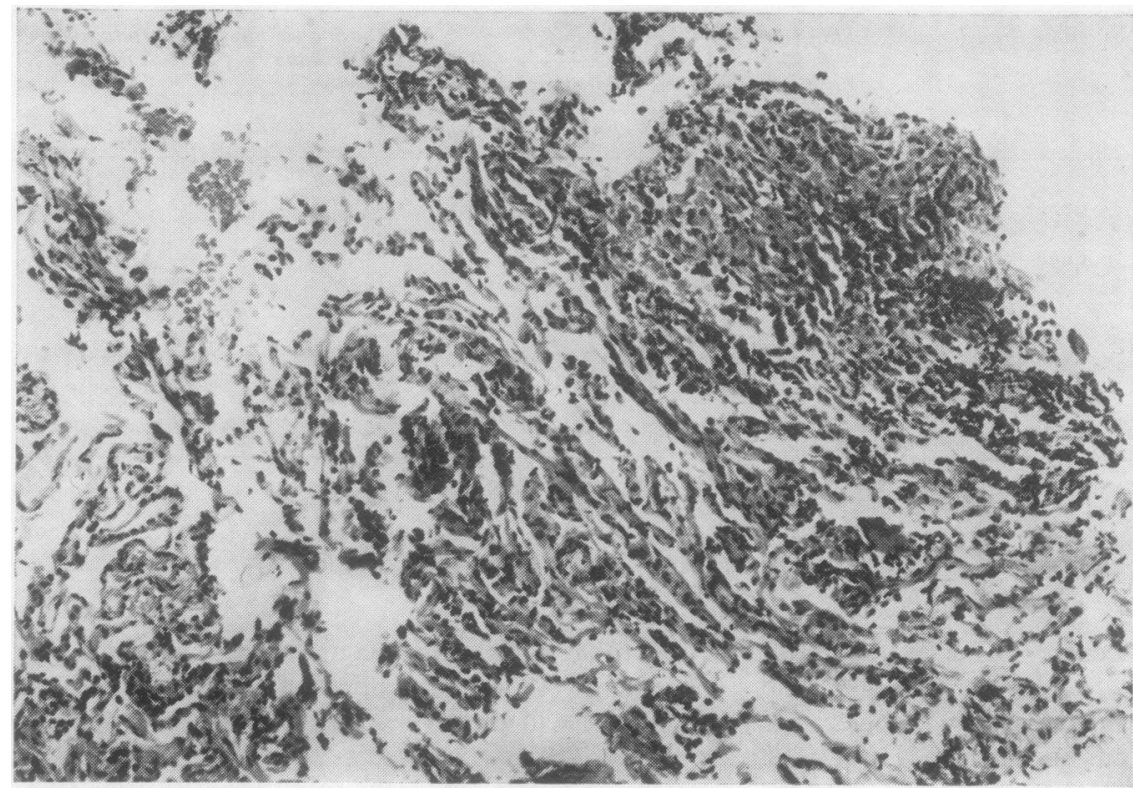

Fig 3 Lung biopsy specimen (case 4) showing early granuloma formation. $\times 95$

well tolerated intravenously and, although nine of our 11 patients have shown evidence of granuloma formation in one or more organs, the only consistent complication they have had has been transient pyrexia following injection. One patient had a raised alkaline phosphatase but no other biochemical or clinical evidence of liver disease. One of the two patients who developed jaundice was terminal and therefore not evaluable, and jaundice in a second patient was probably related to an oral contraceptive.

The mechanism of granuloma formation is uncertain, but it seems likely that it represents a hypersensitivity reaction (Hunt et al, 1973; Muggleton et al, 1975), possibly to dead organisms contained in the BCG vaccine, and the use of a preparation containing a relatively low concentration of dead organisms, such as that used in our study, has been recommended (Muggleton et al, 1975). Disseminated BCG disease did not occur in our patients and, with the possible exception of a patient reported by Hunt et al (1973) (case 2), examples have been confined to immunoincompetent patients, usually suffering from hypogammaglobulinaemia or agammaglobulinaemia (Wallgren, 1955; Bouton et al, 1963; Bonnevier et al, 1964; Carlgren et al, 1966). Although Hunt et al (1973) did not consider their patients to be immunoincompetent, nevertheless all three were PPD negative. The most extensive and well-formed granulomas in our study occurred in patients who were also PPD negative initially, and until the relevance of these findings becomes more clear, great care should be taken when using BCG in this group. Antihistamine pretreatment should be routine when using BCG by intratumour (Sparks $\stackrel{\circ}{\circ}$ et al, 1973) or intravenous (Muggleton et al, 1975) $\overrightarrow{\vec{A}}$ injection. If used by the intravenous route the 3 careful procedure reported by us (Whittaker et al, 1973) may reduce unwanted side effects.

The place of BCG in the treatment of malignant disease remains unestablished and, although an? increased incidence of second remissions in patients 3 with acute leukaemia has been reported (Freemanet al, 1973; Hamilton Fairley, 1975), its potential dangers require that great care should be taken in its use.

We thank Dr J. Marks, Director, Tuberculosis Reference Laboratory, for helpful advice and our $\triangle$ colleagues in South Wales for referring their patients. N

AJS is supported by a grant from the Medical N Research Council.

\section{References}

Bonnevier, J. O, Killander, J., Olding, L and Vahlquist, (1964). Congenital agammaglobulinaemia in the brother of a boy who died of generalized BCG infection. Acta $\frac{\overrightarrow{\mathrm{D}}}{\mathrm{a}}$ paediat. (Uppsala), 53, 55-64.

Bouton, J., Mainwaring, D., and Smithells, R. W. (1963). B.C.G. dissemination in congenital hypogammaglobulinaemia. Brit. med. J., 1, 1512-1515. 
Carlgren, L. E., Hansson, C. G., Henricsson, L., and Wåhlén, P. (1966). Fatal BCG infection in an infant with congenital lymphocytopenic agammaglobulinemia. Acta paediat. scand., 55, 636-644.

Freeman, C. B., Harris, R., Geary, C. G., Leyland, M. J., MacIver, J. E., and Delamore, I. W. (1973). Active immunotherapy used alone for maintenance of patients with acute myeloid leukaemia. Brit. med. J., 4, 571.

Gormsen, H. (1956). On the occurrence of epithelioid cell granulomas in the organs of BCG-vaccinated human beings. Acta Path. microbiol. scand., supplement 111, pp. 117-120.

Gutterman, J. U., Hersh, E. M., Rodriguez, V., McCredie, K. B., Mavligit, G., Reed, R., Burgess, M. A., Smith, T., Gehan, E., Bodey, G. P., and Freireich, E. J. (1974a). Chemoimmunotherapy of adult acute leukaemia: prolongation of remission in myeloblastic leukaemia with B.C.G. Lancet, 2, 1405-1409.

Gutterman, J. U., Mavligit, G., Gottlieb, J. A., Burgess, M. A., McBride, C. E., Einhorn, L., Freireich, E. J., and Hersh, E. M. (1974b). Chemoimmunotherapy of disseminated malignant melanoma with dimethyl triazeno imidazole carboxamide and Bacillus Calmette-Guérin. New Engl. J. Med., 291, 592-597.

Hamilton-Fairley, G. (1975). Immunotherapy in the management of leukaemia. Brit. J. Haemat., 31, supplement, 181-192.

Hunt, J. S., Silverstein, M. J., Sparks, F. C., Haskell, C. M., Pilch, Y. H., and Morton, D. L. (1973). Granulomatous hepatitis: a complication of B.C.G. immunotherapy. Lancet, 2, 820-821.
MRC Working Party on the Evaluation of Different Methods of Therapy in Leukaemia (1963). First Report. Treatment of acute leukaemia in adults: comparison of steroid therapy at high and low dosage in conjunction with 6-mercaptopurine. Brit. med. J., 1, 7-14.

Muggleton, P. W., Prince, G. H., and Hilton, M. L. (1975). Effect of intravenous B.C.G. in guinea pigs and pertinence to cancer immunotherapy in man. Lancet, 1, 1353-1355.

Powles, R. L., Crowther, D., Bateman, C. J. T., Beard, M. E. J., McElwain, T. J., Russell, J., Lister, T. A., Whitehouse, J. M. A., Wrigley, P. F. M., Pike, M., Alexander, P., and Hamilton-Fairley, G. (1973). Immunotherapy for acute myelogenous leukaemia. Brit. J. Cancer, 28, 365-376.

Sparks, F. C., Silverstein, M. J., Hunt, J. S., Haskell, C. M. Pilch, Y. H. and Morton, D. L. (1973). Complications of BCG immunotherapy in patients with cancer. New Engl. J. Med., 289, 827-830.

Ström, L., and Widström, G. (1951). Quelques expériences concernant l'immunité antituberculeuse, effectuées à l'aide de bacilles radio-actifs. Acta paediat. (Uppsala), 40, 213-217.

Vogler, W. R., and Chan, Y-K. (1974). Prolonging remission in myeloblastic leukaemia by tice-strain Bacillus CalmetteGuérin. Lancet, 2, 128-131.

Wallgren, A. (1955). Should mass vaccination with BCG be discontinued in Scandinavia? Acta paediat. (Uppsala), 44, 237-253.

Whittaker, J. A., Lilleyman, J. S., Jacobs, A., and Balfour, I. (1973). Immunotherapy with intravenous B.C.G. (Letter.) Lancet, 2, 1454. 